\title{
Quality of Life in Uncomplicated Symptomatic Diverticular Disease: Is It Another Good Reason for Treatment?
}

\author{
Giuseppe Comparato $^{a}$ Libera Fanigliulo $^{a}$ Giovanni Aragona ${ }^{a}$ \\ Giulia M. Cavestro $^{a}$ Lucas G. Cavallaro ${ }^{a}$ Gioacchino Leandro $^{b}$ Alberto Pilotto ${ }^{c}$ \\ Giorgio Nervi $^{d}$ Paolo Soliani ${ }^{\mathrm{e}}$ Mario Sianesi ${ }^{\mathrm{e}}$ Angelo Franzéd \\ Francesco Di Mario ${ }^{a}$ \\ ${ }^{a}$ Chair of Gastroenterology, University of Parma, ${ }^{b}$ Gastroenterological Hospital 'S. De Bellis' IRCCS, Castellana \\ Grotte, Bari, 'Department of Geriatrics, Casa Sollievo della Sofferenza, Istituto di Ricovero e Cura a Carattere \\ Scientifico, San Giovanni Rotondo, dGastroenterology and Endoscopy Unit, Azienda Ospedaliera, Parma, and \\ e Department of General Surgery and Organ Transplantation, University of Parma, Parma, Italy
}

\section{Key Words}

Diverticular disease - Diverticular disease, quality of life •

Diverticula $\cdot$ Mesalazine

\begin{abstract}
Background: Quality of life (QoL) is becoming a major issue in the evaluation of any therapeutic intervention. Aims: To assess the QoL in patients with uncomplicated symptomatic diverticular disease (DD) and to elucidate the influence of two different treatments either on symptoms or QoL. Materials and Methods: 58 outpatients affected by uncomplicated symptomatic DD, admitted in our Gastroenterological Unit from October 2003 to March 2004, were enrolled. Patients were randomly assigned to two different treatments consisting of rifaximin or mesalazine for 10 days every month for a period of 6 months. QoL was evaluated by means of an SF-36 questionnaire and clinical evaluation was registered by means of a global symptomatic score (GSS) at baseline and after 6 months. Results: At baseline, lower values in all SF-36 domains were confirmed in patients with DD. Both rifaximin and mesalazine groups showed a significant reduc-
\end{abstract}

tion of their mean GSS ( $p<0.01$ and $p<0.001$, respectively) and improvement of SF-36 mean scores after therapy, even though treatment with mesalazine showed better results. Conclusions: DD has a negative impact on QoL. Cyclic treatment with poorly absorbable antibiotics or anti-inflammatory drugs relieves symptoms and improves QoL.

Copyright $\odot 2007$ S. Karger AG, Basel

\section{Introduction}

Acquired diverticular disease (DD) of the colon is very common in developed countries and its prevalence increases with age, varying from less than $10 \%$ in subjects $<40$ years to an estimated $50-66 \%$ of patients $>80$ years [1]. According to a recent report by the American Gastroenterological Association on the burden of digestive illnesses in the USA, DD represents, in terms of direct and indirect costs, the fifth most important gastrointestinal disease with a mortality rate of 2.5 per 100,000 per year [2].

\section{KARGER}

Fax +41613061234

E-Mail karger@karger.ch

www.karger.com
(C) 2007 S. Karger AG, Basel

0257-2753/07/0253-0252\$23.50/0

Accessible online at:

www.karger.com/ddi
Prof. Francesco Di Mario

Università degli Studi di Parma, Dipartimento di Scienze Cliniche

Sezione di Gastroenterologia, Via Gramsci 14

IT-43100 Parma (Italy)

Tel. +390521 702 772, Fax +390521 291 582, E-Mail francesco.dimario@unipr.it 
To refer to an acquired alteration present in about twothirds of the elderly as a 'disease' might seem to be inaccurate, particularly as in the majority of patients colonic diverticula are asymptomatic (diverticulosis) [1]. Nevertheless, an estimated $20 \%$ of affected individuals develop symptoms in their lifetime, such as abdominal pain and/ or discomfort, bloating and disturbance of bowel habits. This clinical condition is termed diverticular disease [3], which may be symptomatic uncomplicated, recurrent symptomatic, or complicated [4-6]. Inflammation of the bowel surface leads to a condition termed uncomplicated diverticulitis. Some authors emphasize that clinical diverticulitis virtually always represents a microperforation, even if colonic mucosa appears macro- and microscopically normal, despite considerable inflammation of the pericolonic tissue [7]. The presence of free perforation, fistula, abscesses or obstruction is termed complicated acute diverticulitis.

DD treatment is aimed at relieving symptoms and preventing major complications [8]. Antibiotics are widely used in the treatment of diverticulitis [3] and, in a subset of patients with symptomatic DD where an inflammatory component may be clinically suspected, a course of antibiotics is advisable [8].

Rifaximin (a broad-spectrum, poorly absorbable antibiotic) appeared to be of some advantage in obtaining relief of symptoms in uncomplicated DD $[9,10]$ and in reducing the incidence of the main complications of this disease $[11,12]$. The rationale for antibiotic therapy in these patients is the role of intestinal microflora in determining symptoms by fiber degradation and gas production [13].

Mucosal inflammation seems to play an important role in the etiopathogenesis of diverticulitis by an imbalance among proinflammatory (IL-1, TNF) and anti-inflammatory (IL-1ra, IL-4, IL-10, IL-11) cytokines [14], with a consequent increase in the intramucosal secretion of nitric oxide [15]. Luminal mucosal inflammation may also occur not only in the acute attacks of diverticulitis and peridiverticulitis, but also, although unusually, in uncomplicated DD $[16,17]$. This kind of diverticular colitis is wholly confined to the segment affected by DD and may closely mimic inflammatory bowel disease (IBD) with its complex phlogistic characteristics [18]. Many of these cases of diverticular colitis seem to respond favorably to treatment similar to that given for IBD [16]. Recently, mesalazine appeared to be of some advantage in obtaining symptom relief in uncomplicated DD and in reducing the incidence of the main complications of such a disease.

Treatment in Diverticular Disease
Four clinical studies have reported that supplementary treatment with mesalazine in patients with colonic DD or with recurrent diverticulitis proved to be well tolerated and promising for the management of such diseases [19-22]. However, the success of the therapeutic modalities has been seen only from a medical point of view, but successful medical therapy reflects only one aspect of the multidimensional approach to these patients, which is also composed of the sensitive and functional aspects of everyday life.

Health-related quality of life (QoL), subjectively perceived by patients, is becoming a major issue in the evaluation of any therapeutic intervention, mainly in patients with chronic disease where the aim of therapy is to keep patients either symptom-free or to reduce the discomfort caused by the disease. To date, only a few studies have investigated QoL in DD [23]. The aim of this study was to assess QoL in a group of patients with uncomplicated $\mathrm{DD}$; we also aimed to elucidate the influence of two schedules of medical treatment either on symptoms evaluated by means of a symptomatic score or QoL by means of a validated questionnaire (SF-36 Italian version).

\section{Materials and Methods}

58 consecutive outpatients ( 31 males, 27 females; mean age $67.28 \pm 10.23$, range $48-92$ years), affected by uncomplicated symptomatic DD admitted from October 2003 to March 2004 in our Gastroenterological Unit, were enrolled.

The diagnosis of colonic diverticulosis was established by means of a double contrast barium enema or endoscopy and all patients presented symptoms attributable to DD of the colon such as upper and/or lower abdominal pain/discomfort, bloating, tenesmus, diarrhea, abdominal tenderness, fever, dysuria. Exclusion criteria were solitary diverticulum of the colon, diverticulitis, previous colonic or abdominal major surgery, colonic or extracolonic cancer, use of antibiotics in the previous 4 weeks, chronic hematological and/or hepatic and/or renal diseases, immunodeficiency, pregnancy or lactating, proven intolerability to rifaximin or mesalazine and a questionable ability to cooperate.

QoL was evaluated by means of an SF-36 questionnaire. The Medical Outcome Study (MOS) 36-Item Short-Form Health Survey (SF-36, Italian version 1.6) questionnaire is well known for its comprehensiveness, brevity and high standards of reliability and validity [24-26]. We chose the SF-36 questionnaire over other generic health-related QoL measures because it has been demonstrated to have excellent reliability and validity when employed in several medical conditions [26-29]. It is also used in other gastrointestinal disorders [30-36] and, finally, because an Italian version has been fully validated [37]. The SF-36 provides an estimate of perceived health status and well-being, and it is based on 36 multiple-choice questions, measuring eight different domains: four in the area of physical health: physical functioning $(\mathrm{PF})$, role limitation-physical (RP), bodily pain (BP) and general health 
Table 1. Demographic and clinical characteristics of the 58 patients at baseline (all differences not significant)

\begin{tabular}{lll}
\hline & Rifaximin group & Mesalazine group \\
\hline Patients (pts) & 27 & 31 \\
Dosage, mg b.i.d. & 12 pts: 200 & 15 pts: 400 \\
& 15 pts: 400 & 16 pts: 800 \\
Age (range) & $67.53 \pm 10.28(48-92)$ & $65.87 \pm 11.24(45-85)$ \\
Global symptomatic score & $9.78 \pm 4.47$ & $10.45 \pm 4.43$ \\
\hline
\end{tabular}

$(\mathrm{GH})$, and four in the area of mental health: role limitation-emotional (RE), vitality (VT), mental health $(\mathrm{MH})$ and social functioning (SF).

All patients included in this study were fluent in the Italian language and the questionnaire was administered according to recommendations suggested by the user's manual [38].

The control group for the SF-36 included 2,031 subjects randomly sampled from electoral lists, independent of their health status, and data were published in 1998 to validate the SF-36 Italian version. Therefore, the values of this group represent the average of health-related QoL of the general Italian population [39]. We compared QoL in the DD group versus the Italian normative group and analyzed the relationship between sex or age (cut-off $>65$ years) and QoL in uncomplicated symptomatic DD.

Patients were also randomly assigned to different treatment regimens consisting of rifaximin (at the dosage of 200 or $400 \mathrm{mg}$ b.i.d.) or mesalazine ( 400 or $800 \mathrm{mg}$ b.i.d.) for 10 days every month for a period of 6 months. No selective dietary regimen was prescribed at entry except recommendation to follow a high-fiber diet.

The SF-36 questionnaire was performed in all treated patients after 6 months to evaluate the influence of several schedules of treatment on QoL. Clinical evaluation was also performed at baseline and after therapy by clinical visit and a symptomatic score was registered taking into account 11 clinical variables (upper abdominal pain/discomfort, lower abdominal pain/discomfort, bloating, tenesmus, diarrhea, abdominal tenderness, fever, general illness, nausea, emesis, dysuria) scored as: $0=$ no symptom, 1 = mild, symptoms easily tolerated, 2 = moderate, symptoms sufficient to cause interference with usual daily activities, 3 = severe, incapacitating symptoms with inability to perform normal activities. A global symptomatic score (GSS), calculated by the sum of each symptom score, was assigned to each patient at every clinical evaluation (maximum score $=33$ ). It was assessed to evaluate the efficacy of administered therapy on overall severity of combined symptoms. It therefore reflects overall clinical conditions of patients during clinical follow-up.

\section{Statistical Methods}

Demographic and clinical characteristics were shown as mean $\pm \mathrm{SD}$ and range if continuous variables, or as absolute and percent frequencies if discrete variables. The score of each parameter of the SF-36 scale in the DD group vs. general Italian population and among the subgroups of therapy was analyzed by means of non-parametric tests: Mann-Whitney test. Variations of both mean GSS and the mean scores of the domains in SF-36 questionnaire were analyzed by means of non-parametric tests: Wilcoxon signed-rank test.

\section{Results}

58 patients fulfilled the inclusion criteria and were randomly assigned to different treatment regimens: 27 patients with rifaximin (12 patients at the dosage of 200 $\mathrm{mg}$ b.i.d. and 15 patients at the dosage of $400 \mathrm{mg}$ b.i.d.), 31 patients with mesalazine (15 patients at the dosage of $400 \mathrm{mg}$ b.i.d. and 16 patients at the dosage of $800 \mathrm{mg}$ b.i.d.) for 10 days every month for a period of 6 months (table 1).

At baseline, patients with DD had mean scores below the optimal scores of the questionnaire in all domains when compared with the Italian normative group, although a statistically significant difference was found for four of eight domains (RP, BP, VT, RE) (table 2). There was no difference in the mean scores of all domains between the two sexes and between the two subgroups of age (cut-off $>65$ years) (table 3 ).

After 6 months of therapy the SF-36 mean score of the enrolled patients improved for almost all domains after treatment both in physical and mental performances with statistically significant differences for: role limitationphysical (RP): $80.17 \pm 29.53$ vs. $61.64 \pm 38.39, \mathrm{p}<0.01$; bodily pain (BP): $73.67 \pm 22.01$ vs. $65.81 \pm 24.25, \mathrm{p}=$ 0.04; general health $(\mathrm{GH}): 70.05 \pm 24.42$ vs. $61.74 \pm 23.79$, $\mathrm{p}=0.01$, and social functioning (SF): $85.43 \pm 18.8$ vs. $71.14 \pm 23.82, \mathrm{p}=0.001$ (fig. 1). We also found a statistically significant reduction of their mean GSS after treatment $(10.14 \pm 4.42$ at baseline vs. $6.83 \pm 3.38$ at 3 months: $\mathrm{p}<0.001$ ) (fig. 2; table 4). No statistically significant differences were found in SF-36 mean scores between rifaximin and mesalazine group at baseline (fig. 3).

Both rifaximin and mesalazine groups improved their SF-36 mean score for almost all domains after treatment as shown in figures 4 and 5, respectively. In the rifaximin group significant differences were found both in physical (RP: $77.78 \pm 32.77$ vs. $61.11 \pm 37.55, \mathrm{p}=0.04$ ) and in mental performances (SF: $84.7 \pm 15.47$ vs. $72.89 \pm 23.75$, $\mathrm{p}=0.03$ ); in the mesalazine group significant differences were found for PF $(87.58 \pm 16.22$ vs. $79.03 \pm 21.46, \mathrm{p}<$ 
Fig. 1. SF-36 mean scores in the DD group at baseline and after 6 months of treatment.

Table 2. SF-36 scores in the DD group versus Italian normative population before therapy

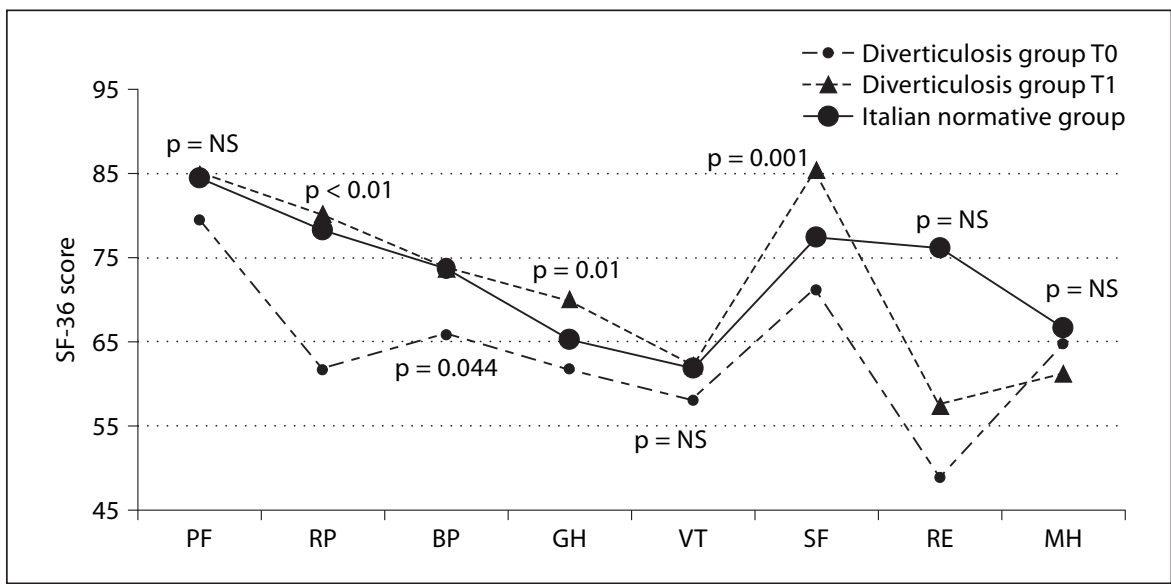

\begin{tabular}{llll}
\hline SF-36 scale & DD group T0 & $\mathrm{p}$ & Italian normative group \\
\hline PF & $79.40 \pm 19.74$ & NS & $84.46 \pm 23.18$ \\
RP & $61.64 \pm 38.39$ & 0.015 & $78.21 \pm 35.93$ \\
BP & $65.81 \pm 24.25$ & 0.014 & $73.67 \pm 27.65$ \\
GH & $61.74 \pm 23.79$ & NS & $65.22 \pm 22.18$ \\
VT & $57.96 \pm 22.66$ & 0.012 & $61.89 \pm 20.69$ \\
SF & $71.14 \pm 23.82$ & NS & $77.43 \pm 23.34$ \\
RE & $48.84 \pm 43.31$ & 0.011 & $76.16 \pm 23.34$ \\
MH & $64.76 \pm 22.78$ & NS & $66.59 \pm 20.89$ \\
\hline
\end{tabular}

p value: Mann-Whitney test, DD group vs. normative group.

Table 3. SF-36 scores according to sex and age

\begin{tabular}{|c|c|c|c|c|c|c|}
\hline \multirow[t]{2}{*}{ SF-36 scale } & \multicolumn{3}{|l|}{ Sex } & \multicolumn{3}{|l|}{ Age } \\
\hline & female $(n=27)$ & male $(\mathrm{n}=31)$ & $\mathrm{p}$ & $\leq 65$ years $(\mathrm{n}=25)$ & $>65$ years $(n=33)$ & $\mathrm{p}$ \\
\hline $\mathrm{RP}$ & $60.00 \pm 37.96$ & $64.13 \pm 39.76$ & NS & $62.50 \pm 32.40$ & $59.85 \pm 42.36$ & NS \\
\hline BP & $63.46 \pm 26.5$ & $69.39 \pm 20.4$ & NS & $65.29 \pm 22.97$ & $65.64 \pm 25.65$ & NS \\
\hline $\mathrm{GH}$ & $57.63 \pm 24.43$ & $68.00 \pm 21.83$ & NS & $64.17 \pm 21.38$ & $59.36 \pm 25.63$ & NS \\
\hline $\mathrm{RE}$ & $51.11 \pm 42.8$ & $45.39 \pm 44.88$ & NS & $53.29 \pm 35.82$ & $44.06 \pm 42.95$ & NS \\
\hline $\mathrm{MH}$ & $60.23 \pm 23.34$ & $71.65 \pm 20.5$ & NS & $70.50 \pm 20.46$ & $60.00 \pm 23.75$ & NS \\
\hline
\end{tabular}

Table 4. GSS in DD group before and after therapy

\begin{tabular}{lrll}
\hline & GSS T0 & GSS T1 & p \\
\hline DD group & $10.14 \pm 4.42$ & $6.83 \pm 3.38$ & $<0.001$ \\
Rifaximin group & $9.78 \pm 4.47$ & $8.04 \pm 3.65$ & $<0.01$ \\
Mesalazine group & $10.45 \pm 4.43$ & $5.77 \pm 2.76$ & $<0.001$
\end{tabular}

$\mathrm{p}$ value: Wilcoxon test.
$0.05), \mathrm{RP}(82.26 \pm 26.77$ vs. $62.1 \pm 39.72, \mathrm{p}=0.034)$ and $\mathrm{GH}(76.64 \pm 22.91$ vs. $61.74 \pm 27.65, \mathrm{p}=0.01)$ in physical and for $S F(86.06 \pm 21.53$ vs. $69.61 \pm 24.17, \mathrm{p}=0.006)$ in mental performances.

Treatment with mesalazine showed better results than rifaximin in increasing mean scores with statistically significant differences for two domains that are correlated with physical performance: physical functioning (PF): 
Fig. 2. GSS of symptoms at baseline and after 6 months of treatment.

Fig. 3. SF-36 scores in the rifaximin group before and after therapy.

Fig. 4. SF-36 scores in the mesalazine group before and after therapy.
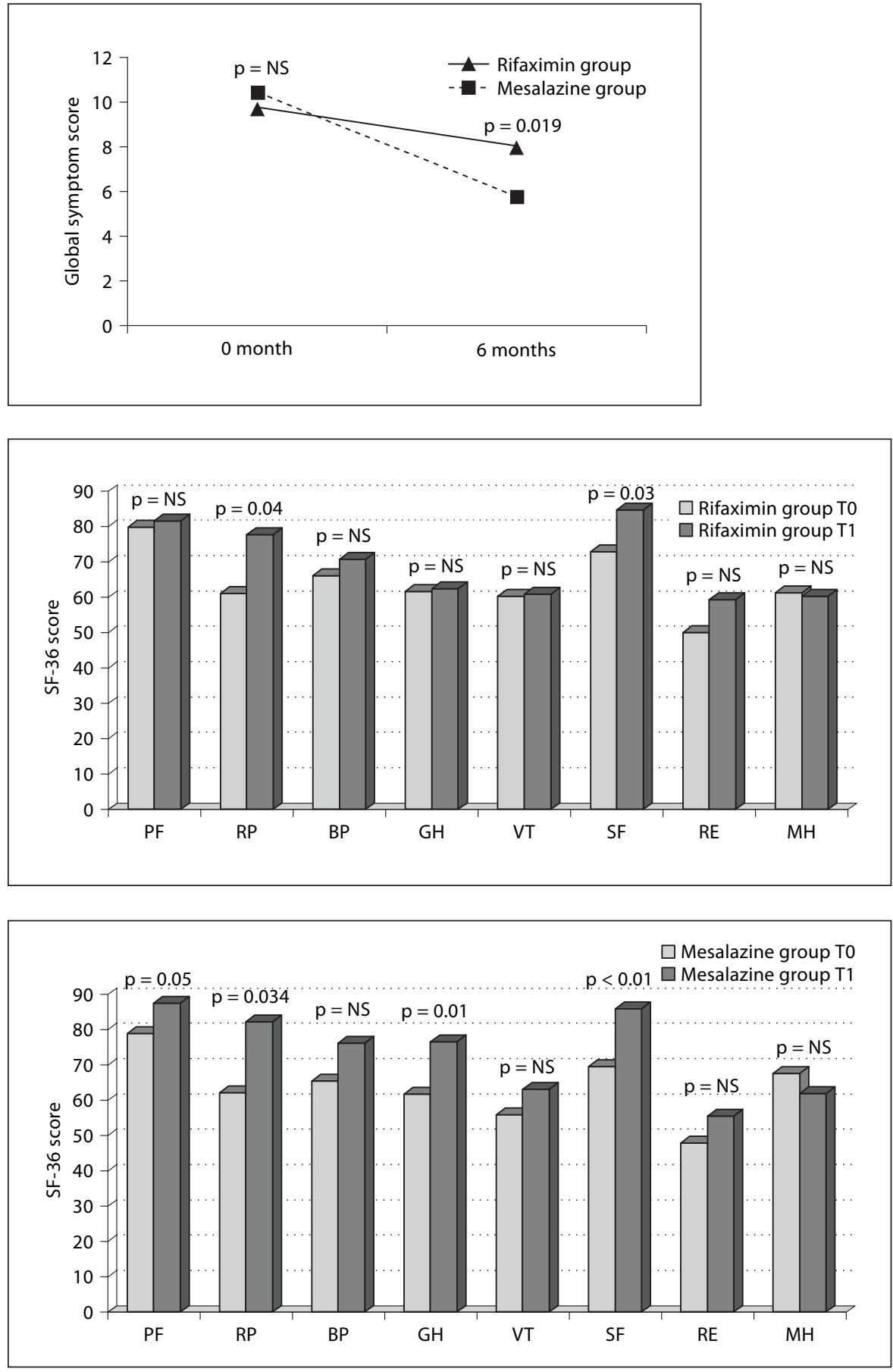

$87.58 \pm 16.22$ vs. $81.67 \pm 15.06, \mathrm{p}<0.05$, and general health (GH): $76.64 \pm 22.91$ vs. $62.48 \pm 24.31, \mathrm{p}=0.01$ (fig. 6). Moreover, further analysis was performed comparing the mean GSS of patients treated with rifaximin versus patients treated with mesalazine. After 6 months of therapy, both the rifaximin group and mesalazine group showed a highly significant reduction of their mean GSS ( $p<0.01$ and $p<0.001$, respectively), even though treatment with mesalazine showed better results than rifaximin in diminishing mean GSS at the 6-month follow-up $(\mathrm{p}<0.019)$. 
Fig. 5. SF-36 scores in the rifaximin group vs. mesalazine group at baseline.

Fig. 6. SF-36 scores in the rifaximin group vs. mesalazine group after therapy.
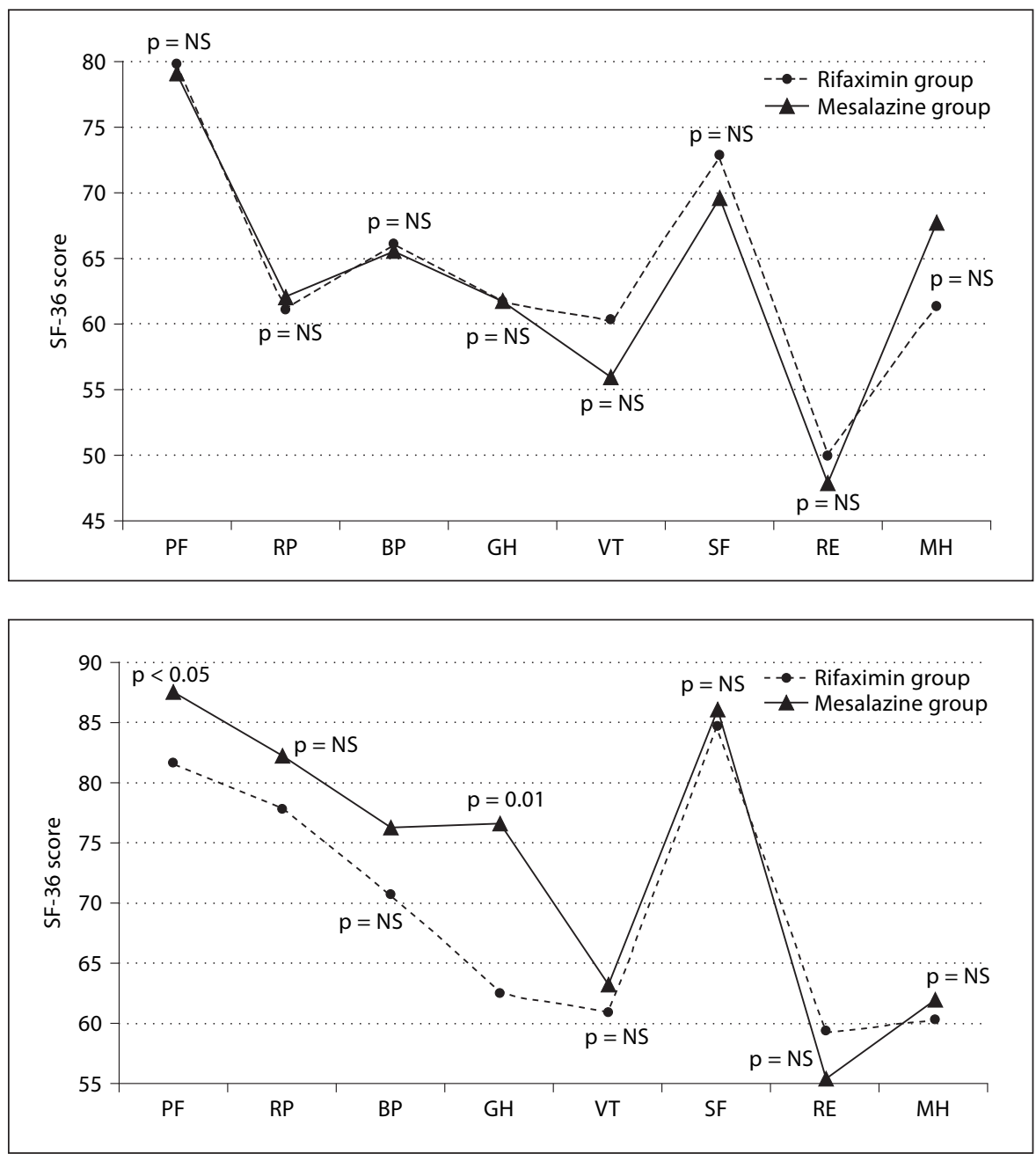

\section{Discussion}

QoL measurement is becoming an increasingly important factor in the assessment and management decision-making of both malignant and benign surgical and gastroenterological conditions. DD is common in western countries and carries significant risk of morbidity and mortality. However, only one study investigated QoL in DD [23]. The authors concluded that DD has a negative impact on QoL. They used a questionnaire which has been validated for patients with IBD (Guyatt questionnaire).

In our study we investigated QoL in uncomplicated symptomatic DD using the SF-36 questionnaire. We confirmed that patients with DD have a substantially impaired QoL compared with the Italian normative group. This study also showed no differences in QoL between the two sexes and between younger and older patients (we considered a cut-off of $>65$ years). These findings agree with those of Bolster and Papagrigoriadis [23].

DD treatment is aimed at relieving symptoms and preventing major complications. Several studies investigated this endpoint using different classes of drugs. To date, no studies have investigated the influence of therapy on QoL.

In our study, patients were randomly assigned to two treatment regimens consisting of a non-absorbable antibiotic (rifaximin) or anti-inflammatory (mesalazine). After 6 months of therapy we found an improvement of the mean score in almost all domains of the SF-36 questionnaire both in physical and mental performances. No significant differences were found between the rifaximin and mesalazine groups in mean scores of the QoL questionnaire and mean GSS at baseline. Our study agrees 
with others in that cyclic therapy with an anti-inflammatory or non-absorbable antibiotic resulted in effectively relieving symptoms in such patients. Indeed, 6 months of cyclic administration of mesalazine is as effective as rifaximin in diminishing mean GSS, but mesalazine-treated patients showed a lower GSS than rifaximin patients.

Both mesalazine and rifaximin group patients improved mean scores of almost all domains of the SF-36 questionnaire after therapy showing a significant improvement in physical and mental status. Finally, mesalazine-treated patients showed a higher SF-36 mean score in almost all domains than rifaximin patients after 6 months of therapy, but a marked improvement was registered in physical status.
In conclusion, our study confirmed DD has a negative impact on QoL both in physical and mental performances. This effect is not influenced by age and sex. A cyclic treatment with poorly absorbable antibiotics or anti-inflammatory drugs relieves symptoms and improves physical and mental performances. Mesalazine-treated patients showed a lower GSS and higher SF-36 mean scores than rifaximin patients. This is the first study that has investigated the impact of therapy on QoL in a chronic condition such as uncomplicated symptomatic DD. It is a preliminary study with a small number of patients, but our findings could justify further research into QoL in $\mathrm{DD}$ as an important primary endpoint to evaluate efficacy of therapy.

\section{References}

$\checkmark 1$ Stollman NH, Baskin JB, for the Ad Hoc Practice Parameters Committee of the American College of Gastroenterology: Diagnosis and management of diverticular disease of the colon in adults. Practice guidelines. Am J Gastroenterol 1999;94: 3110-3121.

2 American Gastroenterological Association: The burden of gastrointestinal disease. Bethesda, AGA, 2001.

-3 Almy TP, Howell DA: Diverticular disease of the colon. N Engl J Med 1980;302:324-331.

$\checkmark 4$ Kohler L, Sauerland S, Neugebauer E, for the Scientific Committee of the European Association for Endoscopic Surgery: Diagnosis and treatment of diverticular disease. Results of a consensus development conference. Surg Endosc 1999;13:430-436.

5 Schwartz JT, Graham DY: Diverticular disease of the large intestine; in Kirsner J, Shorter R (eds): Diseases of the Colon, Rectum and Anal Canal. Baltimore, Williams \& Wilkins, 1998, pp 519-536.

6 Naitove A, Smith RE: Diverticular disease of the colon; in Sleisenger MH, Fordtran TS (eds): Gastrointestinal Disease, ed 5. Philadelphia, Saunders, 1993, pp 1347-1363.

7 Fleischner FG, Ming SC: Revised concepts on diverticular disease of the colon. II. Socalled diverticulitis: diverticular sigmoiditis and perisigmoiditis, diverticular abscesses, fistula and frank peritonitis. Radiology 1965 ; 84:599-609.

8 Torsoli A, Inoue M, Manousos O, Smith A, Van Steensel CJ: Diverticular disease of the colon: data relevant to treatment. Gastroenterol Int 1991;4:3-20.

-9 Papi C, Ciaco A, Koch M, Capurso L, Diverticular Disease Study Group: Efficacy of rifaximin on symptoms of uncomplicated diverticular disease of the colon. A pilot multicentre open trial. Ital J Gastroenterol 1992;24:452-456.
10 Papi C, Ciaco A, Koch M, Capurso L: Efficacy of rifaximin in the treatment of symptomatic diverticular disease of the colon. A multicentre double-blind placebo-controlled trial. Aliment Pharmacol Ther 1995; 9:33-39.

11 Latella G, Pimpo MT, Sottili S, et al: Rifaximin improves symptoms of acquired uncomplicated diverticular disease of the colon. Int J Colorectal Dis 2003;18:55-62.

12 Iosca N, Ferrieri A: Terapia e profilassi con rifaximina degli episodi di diverticolite acuta. Recenti Prog Med 1993;84:42-53.

13 Kurpad AV, Shetty PS: Effects of antimicrobial therapy on faecal bulking. Gut 1997;27: 55-58.

14 Rogler G, Andus T: Cytokines in inflammatory bowel disease. World J Surg 1998;22: 382-389.

15 Izzo AA, Mascolo N, Capasso F: Nitric oxide as a modulator of intestinal water and electrolyte transport. Dig Dis Sci 1998;43:16051620.

16 Gore S, Sheperd NA, Wilkinson SP: Endoscopic crescentic fold disease of the sigmoid colon: the clinical and histopathological spectrum of a distinctive endoscopic appearance. Int J Colorect Dis 1992;7:76-81.

17 Makapugay LM, Dean PJ: Diverticular disease-associated chronic colitis. Am J Surg Pathol 1996;20:94-102.

18 Sheperd NA: Diverticular disease and chronic idiopathic inflammatory bowel disease: associations and masquerades. Gut 1996;38: 801-802.

19 Trespi E, Colla C, Panizza P, et al: Ruolo terapeutico e profilattico della mesalazina (5ASA) nella malattia diverticolare sintomatica del crasso. Minerva Gastroenterol Dietol 1999;45:245-252.
20 Tursi A, Brandimarte G, Daffinà R: Longterm treatment with mesalazine and rifaximin versus rifaximin alone for patients with recurrent attacks of acute diverticulitis of colon. Digest Liver Dis 2002;34:510-515.

21 Brandimarte G, Tursi A: Rifaximin plus mesalazine followed by mesalazine alone is highly effective in obtaining remission of symptomatic uncomplicated diverticular disease. Med Sci Monit 2004;10:PI70PI173.

22 Di Mario F, Aragona G, Leandro G, et al: Efficacy of mesalazine in the treatment of symptomatic diverticular disease. Dig Dis Sci 2005;50:581-586.

-23 Bolster LT, Papagrigoriadis S: Diverticular disease has an impact on quality of life - results of a preliminary study. Colorectal Dis 2003;5:320-323.

24 McHorney CA, Ware JE Jr, Lu JF, Sherbourne CD: The MOS 36-Item Short-Form Health Survey (SF-36). III. Tests of data quality, scaling assumptions, and reliability across diverse patient groups. Med Care 1994;32:4066.

25 McHorney CA, Ware JE Jr, Raczek AE: The MOS 36-Item Short Form Health Survey (SF-36): psychometric and clinical tests of validity in measuring physical and mental health constructs. Med Care 1993;31:247263.

26 Ware JE: SF-36 Health Survey. Manual and Interpretation Guide. Boston, The Health Institute, New England Medical Center, 1993.

27 Keller SD, Ware JE Jr, Hatoum HT, Kong SX: The SF-36 Arthritis-Specific Health Index (ASHI). II. Tests of validity in four clinical trials. Med Care 1999;37:MS51-MS60.

-28 Cox E, Donohue JF, Brown CD, Kataria YP, Judson MA: Health-related quality of life of persons with sarcoidosis. Chest 2004;125: 997-1004. 
29 Birks Y, Roebuck A, Thompson DR: A validation study of the Cardiac Depression Scale (CDS) in a UK population. Br J Health Psychol 2004;9:5-24.

30 VanderZee KI, Sanderman R, Heyink J: A comparison of two multidimensional measures of health status: the Nottingham Health Profile and the RAND 36-Item Health Survey 1.0. Qual Life Res 1996;5:165174.

31 Irvine EJ: Quality of life in inflammatory bowel disease: biases and other factors affecting scores. Scand J Gastroenterol 1995; 208:136-140.

- 32 Yacavone RF, Locke GR III, Provenzale DT, Eisen GM: Quality of life measurement in gastroenterology: What is available? Am J Gastroenterol 2001;96:285-297.
3 Borgaonkar MR, Townson G, Donnelly M, Irvine EJ: Providing disease-related information worsens health-related quality of life in inflammatory bowel disease. Inflamm Bowel Dis 2002;8:264-269.

34 Bianchi G, Loguercio C, Sgarbi D, et al: Reduced quality of life of patients with hepatocellular carcinoma. Dig Liver Dis 2003;35: 46-54.

35 Marchesini G, Bianchi G, Amodio P, et al: Italian Study Group for Quality of Life in Cirrhosis: factors associated with poor health-related quality of life of patients with cirrhosis. Gastroenterology 2001;120:170178.
6 Bamfi F, Olivieri A, Arpinelli F, et al: Measuring quality of life in dyspeptic patients: development and validation of a new specific health status questionnaire: final report from the Italian QPD project involving 4,000 patients. Am J Gastroenterol 1999;94:730738 .

37 Rannard D, Buck D, Jones DE, James OF, Jacoby A: Assessing quality of life in primary biliary cirrhosis. Clin Gastroenterol Hepatol 2004;2:164-174.

38 Apolone G, Mosconi P: The Italian SF-36 Health Survey: translation, validation and norming. J Clin Epidemiol 1998;51:10251036.

39 Apolone G, Mosconi P, Ware JE Jr: Questioniario sullo stato di salute SF-36. Manuale d'uso e guida all'interpretazione dei risultati. Milano, Edizioni Angelo Guerini, 1997. 